\title{
Relationship between Nursing Students' Clinical Learning Environment Satisfaction, their Self-Efficacy and Academic Achievement
}

\author{
Mohamed Saad Saleh, Lecturer \\ Nursing Administration, Faculty of Nursing, Alexandria University
}

\begin{abstract}
The clinical practice is the most significant element of nursing education, which must be practiced in suitable setting. The worth of Clinical Learning Environment is a valid indicator to confirm the value of nursing curriculum. The quality of patient care is only reasonable, if nursing staff have acquired high quality of clinical training during their nursing education and their employment years. Objective: Identify the relationship between nursing students' Clinical Learning Environment satisfaction, their self-efficacy, and academic achievement. Setting: Six clinical training Hospitals namely: Alexandria Main University Hospital, Alexandria New University Hospital, Alexandria Students' University Hospital, El Shatby Pediatric Hospital, El Shatby Obstetric Hospital, and El Maamoura Psychiatric Hospital. Subjects: Nursing students enrolled in different nursing courses and affiliated to Faculty of Nursing - Alexandria University during their four consecutive academic years were recruited in this study $(n=324)$. Tools: Clinical Learning Environment Inventory (CLEI) and College Academic Self-Efficacy Scale (CASES), and Personal Data Tool. Results: More than two thirds of the students were satisfied with their Clinical Learning Environment. Statistically significant positive correlation between Nursing students' Clinical Learning Environment satisfaction, their SelfEfficacy and Academic Achievement in nursing courses existed and also, between students' study year in nursing Faculty, Clinical training specialty, clinical training unit and Clinical Learning Environment satisfaction. A statistically significant positive correlation was detected between students' age, study year in nursing Faculty, type clinical training hospitals, clinical training specialty, type clinical training units and their levels of self-efficacy. Conclusion: Nursing students highlighted negative areas that could be taken into consideration by the faculty members to enhance the Clinical Learning Environment. There is statistically significant positive correlation between Nursing students' Clinical Learning Environment satisfaction, their Self-Efficacy and Academic Achievement in nursing courses. Recommendations: Measurement of nursing students' satisfaction about the Clinical Learning Environment should be conducted in a compassionate and nonthreatening manner. Staff development programs for clinical instructors are needed to promote their skills in providing effective clinical training for nursing students. Opportunities should be allowed for nursing students to express their opinions about effectiveness of Clinical Learning Environment. The clinical instructors should assist nursing students to solve the problems facing them in the Clinical Learning Environment.
\end{abstract}

Keywords: Nursing Students; Clinical Learning Environment; Satisfaction, Self-Efficacy; Academic Achievement.

\section{Introduction}

The clinical practice is the most significant element of nursing education, which must be practiced in suitable setting. The worth of Clinical Learning Environment is a valid indicator to confirm the value of nursing curriculum. The quality of patient care is only reasonable, if nursing staff have acquired high quality of clinical training during their nursing education and their employment years. Nursing staff have a significant responsibility in promoting health of the public ${ }^{(1)}$. The proficiency of nursing staff is founded on their learning, knowledge and skills which they acquired during their nursing education. Nursing progress starts in a college setting and continues in a Clinical Learning Environment, where they primarily be trained on the profession. In nursing, there is a strong requirement for effective clinical 
training that assist in student education in the clinical environment ${ }^{(2)}$.

Clinical Learning Environment has been defined by many as "the place where the students practice and develop their clinical competences including the physical environment, teaching staff, nurses and other health professionals". It is significant for the nursing students' education, clinical competencies, critical judgment, decision making, monitoring skills and academic motivation during their clinical training ${ }^{(3)}$.

The recognition of factors that describe Clinical Learning Environment leads to strategies that enhance desirable student learning outcomes and decreases those which have a negative effect on nursing student's outcomes. Therefore, assessment of Clinical Learning Environment is a responsibility of nursing education administrators. Continuous assessment of Clinical Learning Environment effectiveness will improve the quality of training and enhance nursing students' knowledge and competencies. Furthermore, assessment of Clinical Learning Environment effectiveness will lead to the application of resources in a proficient manner, and will ensure that the clinical practice provides the nursing students the most excellent learning outcomes $^{(4)}$.

The factors that have an impact on nursing students' learning include the following: quality of nursing students' preparation, characteristics of clinical instructors, characteristics of training departments, peer support, past clinical training experiences, availability of adequate physical resources, learning chances, availability of adequate number of teaching staff, chances to demonstrate interpersonal and technical competencies, and nursing students' perceptions. Moreover, providing chances for nursing students to practice intimately with role models will lead to acquisition of the skills required within the work setting $^{(5)}$.
Moreover, the factors that influence clinical training including: emphasis on clinical experience was given similar to knowledge; nursing educators were always involved in clinical training; clinical instructors have adequate clinical experience; nursing educators have skills in applying clinical procedures; availability of different clinical experiences during clinical training; presence of procedure manuals to guide nursing students; enough clinical supervision for students during clinical training; presence of various techniques during clinical training; clinical competencies learned related to recent nursing practice; health team members provided nursing students with enough support during clinical training; objectives of clinical training met at each clinical rotation; availability of a positive Clinical Learning Environment; and finally, availability of enough chances for demonstration of clinical activities ${ }^{(6)}$.

Also, the factors that hinder the clinical training as perceived by nursing students include the following: nursing staff are uncooperative with nursing students, due to poor time management by nursing staff, the number of clinical instructors inadequate for clinical training, additionally high workload of clinical instructors, dissatisfaction of nursing students with their Clinical Learning Environment, atmosphere was not suitable to clinical training and unavailability of resources needed for clinical training, and inadequate consideration to individualization of nursing students. Moreover, the tasks of nursing students in Clinical Learning Environment were unclear; task orientation was not specified, and lack of chances to demonstrate clinical activities. In addition, the interpersonal relationships between health team members were poor ${ }^{(7)}$.

The objectives of clinical training must be congruent with skills and knowledge needed from nursing students. The clinical experience must enhance selfconfidence of nursing students, promote 
their ability to make decisions in clinical practice, enhance their critical thinking skills, promote students' independency, develop communication skills ${ }^{(8)}$. The Clinical Learning Environment which provide nursing students with chances for quality training experiences and enable the nursing graduates to meet the increased demands are appreciated by Nursing students and health team members. The Clinical Learning Environment influence nursing students' clinical experiences, career intentions, satisfaction of nursing students and the extent to which the clinical experiences are perceived as positive by nursing students. Also, Clinical Learning Environment promotes nursing students' confidence and self efficacy and help nursing students to be adequately prepared for clinical practice ${ }^{(9)}$.

Self-efficacy can be defined as "one's belief about ability to perform respective functions" ${ }^{(16)}$. In academic learning environment, self-efficacy means student's ability to execute specific academic activities. Students who had a high selfefficacy level develop higher tendency, endeavor, and competencies in demonstrating academic activities and feel confident of their abilities. Self efficacy can enhance learning strategies of nursing students, especially in tasks which require self-regulation, and expect academic progress outcomes $^{(10)}$.

\section{Self-efficacy considered a}

fundamental factor for academic achievement. Students who had high Selfefficacy level perform hard tasks, and motivated, and finally are likely to attain their personal aims. On the other hand, students with low Self-efficacy level have little ambition which may lead to poor academic achievement $^{(11)}$.

Academic achievement of nursing students is one of the fundamental aims of educational plans. Academic achievement and preventing students from academic failure is one of the fundamental concerns of professors, educational administrators of universities and students' families. High self-efficacy is associated with high internal motivation, continuation of motivation and behaviors directed to development, stability when facing with problems and better problem solving. Some think that there is intimate relationship between self-efficacy and individual performance on providing assigned activities. Additionally, selfefficacy is the average between knowledge and its application. Self-efficacy can lead to more learning and development ${ }^{(12)}$.

Nursing students who had high selfefficacy level use more self-regulating strategies in comparison with nursing students who had low self-efficacy level. Moreover, self-efficient nursing students try more to recognize academic materials, believe deeper on academic materials, and plan for achieving their academic $\operatorname{activities}^{(10)}$.

Yusuf (2011) states that self-efficacy and achievement inspiration plays a significant role in the experience of nursing and professional progress. Therefore; it is significant to understand the self-efficacy level of nursing students. Students with a high self-efficacy level assigned to a task, they make the greatest effort, insistent, study hard and choose difficult activities. Also, nurses who have a high level of self-efficacy view barriers as a chance rather than an obstacle. Moreover, they always able to confront serious situations, rather than to ignore the situations. Also, in other study, someone mentioned that persons who had a high achievement level preferred moderately difficult assignments because these assignments can provide the best opportunity for achievement. Self-efficacy is congruent with successful achievement; this can advance the nursing students' motivation and become more confident to carry out nursing tasks in difficult situations ${ }^{(13)}$. Nowadays, nursing staff face different kinds of demands. To meet these demands, the nursing staff must have a high level of confidence. Moreover, health care team members who have a low confidence 
level cannot provide a high quality of care for their patients. Therefore, self-confidence is considered as a significant factor for achievement in the nursing profession. Nursing students need enough selfconfidence level to learn and have adequate opportunities for demonstration of clinical activities. Therefore, the nursing educators responsible to support the nursing students to develop their self-confidence level ${ }^{(14)}$.

Zahra et al. (2015) stated that students with learning difficulties had a low selfefficacy levels and a low achievement inspiration due to their decreased expectations. Both, achievement motivation and self-efficacy promote the nursing students to use their potentials to the greatest level. Moreover, incompetence of nursing students decreases their ability to achieve educational goals and had a negative effect on academic achievement ${ }^{(15)}$.

Self-efficacy affects the learning, achievement, and inspiration of persons. Higher self-efficacy level resulted in higher achievement through increasing loyalty. Self-efficacy is one of the most significant parameters of academic achievement, and higher self-efficacy leads to higher motivation of persons ${ }^{(16)}$. Nursing students' self-efficacy assists them to become competent in clinical practice. Self-efficacy is a significant indicator to forecast performance of nursing students in clinical settings. Clinical training of competent nursing staff demands courage and dedication $^{(17)}$.

Students with lower self-efficacy levels avoid situations which resulted in failure in the past. When this occurs, it resulted an educational catastrophe in nursing field. This resulted in the students would avoid certain assignments that they perceive may lead to failure during their learning experience. Also, the students may have a lower clinical self-esteem level and may lead to higher attrition rate in the nursing profession ${ }^{(18)}$. If students have selfconfidence in their abilities, they can use their efforts to the greatest extent in various situations. Self-efficacy is fundamental for nursing students and nursing staff. Nursing staff who have lower self-efficacy levels would not take required measures for their patients. In situations that the mistakes have overwhelming consequences for nursing staff, resulted in nursing staff would not accept assignments for which they are not skilled to prevent occurrence of errors. Therefore, students must see achievement on the assignments they had anticipated to be unsuccessful $^{(19)}$.

McLaughlin et al. (2008) studied the relationship between personality and selfefficacy to forecast academic achievement and attrition from nursing education. Results revealed that higher self-efficacy levels resulted in higher academic achievement levels ${ }^{(20)}$. Gibbons (2010) mentioned that nursing students' self-efficacy improved through providing nursing students constructive feedback, continuous support, providing chances to demonstrate clinical activities in laboratories under the guidance and direction of a clinical instructor, providing nursing students with a various clinical activities and encouraging them to demonstrate clinical activities independently until they become competent and skillful ${ }^{(21)}$.

The nursing students should be allowed to convey their satisfaction about Clinical Learning Environment so that adequate corrective measures taken based on nursing students' opinions to meet educational aims ${ }^{(59)}$. Satisfaction of nursing students with Clinical Learning Environment is a significant criterion utilized for the measurement of effectiveness of clinical experience in nursing. So, the researchers carried out this current study to examine the relationship between nursing students' satisfaction about Clinical Learning Environment, their self-efficacy, and academic achievement ${ }^{(22)}$.

\section{Significance of the study:}

Evaluation of Clinical Learning Environment as perceived by nursing students is significant for improvement of 
the effectiveness of clinical nursing practice and better nursing educational experiences. In spite of the significance of the Clinical Learning Environment, the effect of the effectiveness of Clinical Learning Environment on nursing students' achievement during clinical training has not been examined seriously. Additionally, recent studies demonstrate that little information present about the effect of effectiveness of Clinical Learning Environment on nursing students' selfefficacy, and academic achievement.

\section{Aim of the Study}

The aim of this study is to investigate the relationship between nursing students' satisfaction about Clinical Learning Environment, their self-efficacy and academic achievement.

\section{Research Question}

Is there a relationship between nursing students' satisfaction about Clinical Learning Environment, their self-efficacy and academic achievement?

\section{Materials and Method}

\section{Materials}

Design: Descriptive correlational design was used to conduct this study.

Setting: This study conducted in six clinical training Hospitals with twenty four departments where nursing students had their clinical training, which divided as follows: Six clinical training Hospitals namely: Alexandria Main University Hospital, Alexandria New University Hospital, Alexandria Students' University Hospital, El Shatby Pediatric Hospital, El Shatby Obstetric Hospital, and El Maamoura Psychiatric Hospital. The twenty four departments namely: Medical GastroIntestinal Tract Department (male), Medical Gastro-Intestinal Tract Department (female), Medical Blood Diseases Department (male), Medical Blood Diseases Department (female), Surgical Gastro-Intestinal Tract
Department (male), Surgical GastroIntestinal Tract Department (female), Neurosurgical Department (male), Neurosurgical Department (female), Third Intensive Care Unit, First Intensive Care Unit, Seventh floor Intensive Care Unit, Second floor General Intensive Unit, Medical Pediatric Department, Surgical Pediatric Department, Neonatal Intensive Care Unit (NICU), Obstetric Family planning Unit, Obstetric Intensive Care Unit, Neurological Intensive Care Unit, Second Intensive Care Unit, Male Psychiatric Department, Female Psychiatric Department, Male Geriatric Department, Female Geriatric Department, and Outpatient Department.

Subjects: Non-probability, convenience sampling used to conduct this study. The study subjects included first, second, third, and fourth year nursing students $(n=324)$ who had clinical training in previously mentioned clinical training Hospitals and units who were available during the time of data collection.

The sample size was estimated using the EPI info 7.0 program based on these parameters; population size: 1000, possible error $5 \%$, confidence coefficient $95 \%$, and minimal sample size 324 (table 1).

Tools: Two tools were used to conduct this study:

\section{Tool I: Clinical Learning Environment Inventory (CLEI)}

Clinical Learning Environment Inventory (CLEI) was developed by (Chan 2001, 2002), and used to assess nursing students' perception of the effectiveness of Clinical Learning Environment ${ }^{(23,24)}$. The instrument is based on a conceptual framework that contains three fundamental dimensions: a relationship dimension, a personal dimension, and a system maintenance and system change dimension (Chan 2001) $^{(23)}$. CLEI contains 42 items that are divided into six subscales with seven items each for each subscale as follows: 
Personalization means emphasis on chances for student to interact with their clinical instructor and on concern for student's personal welfare; individualization is the extent to which students have the opportunity to make decisions and are treated differentially according to ability; innovation means the extent to which clinical instructor plans updated and interesting clinical ward experiences, teaching strategies, educational activities and patient allocations; involvement is the extent to which students participate actively and attentively in hospital ward activities; task orientation denotes the extent to which clinical ward activities are clear and organized; satisfaction means the extent to which students are enjoyed with Clinical Learning Environment.

The 42 items are a combination of positive and negative items. Responses to each item are rated on a four-point Likerttype scale with the following response alternatives: 5 (strongly agree), 4 (agree), 2 (disagree) and 1 (strongly disagree). Omitted or invalid responses were rated 3 as recommended by Chan (2001). To calculate mean scores, the scores on negative items were reversed. Higher scores on each subscale indicate better students' satisfaction with Clinical Learning Environment ${ }^{(23)}$.

The cut off for The Clinical Learning Environment Inventory (CLEI) as follows:

- $<40 \%=$ Low level of CLE effectiveness as perceived by nursing students.

- $40 \%-69 \%=$ Moderate level of CLE effectiveness as perceived by nursing students.

- $\geq 70 \%=$ High level of CLE effectiveness as perceived by nursing students.

Two similar forms of the CLEI was developed by Chan (2001), one that asked students to score with their actual clinical experiences in the Clinical Learning
Environment in mind (the actual form) and one where students were asked to score based on how they preferred the Clinical Learning Environment to be (the preferred form). In this current study, we only used the actual form ${ }^{(23)}$. Internal consistency estimated with Cronbach's Alpha in the present study, the overall reliability for the Clinical Learning Environment Inventory (CLEI) was 0.957 and Cronbach's alpha for the subscale of personalization was 0.774 , student involvement was 0.731 , satisfaction was 0.859 , Task orientation was 0.832 , teaching innovation was 0.788 and Individualization was 0.750 .

Tool II: The College Academic SelfEfficacy Scale (CASES)

The College Academic Self-Efficacy Scale (CASES) was developed by Owen and Froman (1998), and used to assess nursing students' academic self-efficacy ${ }^{(25)}$. The College Academic Self-Efficacy Scale (CASES) was designed to assess nursing students' confidence level in their ability to complete certain behaviors related to college academic success. The instrument contained questions about students' confidence level is in the ability to ask questions in large or small groups, take tests, study appropriately, run for student government, and write a high quality paper among others. This instrument was composed of thirty-three questions without dimensions or subscales and used a Likert-type scale with a range of $\mathrm{A}$ (or $5=$ Quite a lot of confidence), B (or $4=\mathrm{A}$ lot of confidence), $\mathrm{C}$ (or 3 = neutral), $\mathrm{D}$ (or $2=\mathrm{A}$ little confidence) and $\mathrm{E}$ (or 1 = very little confidence) ${ }^{(25)}$.

A reliability analysis was done for the instrument and a Cronbach's Alpha of the instrument was 0.875 . The instrument is scored by summing the scores on each question and dividing by the number of questions in the instrument. Nursing students had the ability to score between a range of 33 points (the lowest amount of confidence) and 165 points (the highest amount of confidence). The cut off for The 
College Academic Self-Efficacy Scale (CASES) as follows:

- $<40 \%=$ Low level of nursing students' self-efficacy.

- $40 \%-69 \%=$ Moderate level of nursing students' self-efficacy.

- $\geq 70 \%=$ High level of nursing students' self-efficacy.

In addition, questions related to sociodemographic characteristics about nursing students developed by the researcher such as: age, gender, study year in nursing faculty, clinical training hospital, clinical training unit and type of clinical training. Students' grades of all nursing courses were recorded by the researcher from the student's affairs department.

\section{Method}

- An official permission obtained from the dean of Faculty of Nursing to collect the necessary data.

- The tools of the study used in English form, and tested for their content validity by a panel of five experts in the field of the study.

- The tools of the study tested for their reliability by Chronbach's Alpha Coefficient test.

- A Pilot study carried out on $10 \%$ of Nursing students $(n=32)$ that will be not included in the study in order to check and ensure the clarity, applicability and feasibility of the tools and identify obstacles and problems that may be encountered during data collection and the necessary modifications were done.

- Data collection for this study conducted by the researcher through self-administered questionnaire. It was hand delivered to the study subjects, they were asked to return it back to the researcher at the study setting.

- After completion of data collection, the appropriate statistical analysis was used to determine the relationship between nursing students' satisfaction about clinical learning environment, their self-efficacy and academic achievement.

\section{Ethical considerations:}

A written informed consent from the study subjects was obtained. Confidentiality of the data, privacy, and anonymity of the study subjects were maintained. The study subjects' right to withdraw from the study was assured.

\section{Statistical Analysis}

Data were fed to the computer and analyzed using IBM SPSS software package version 20.0. (Armonk, NY: IBM Corp) Qualitative data were described using number and percent. Quantitative data were described using mean, standard deviation. Significance of the obtained results was judged at the 5\% level. The used tests were as follows: Student t-test was used for normally distributed quantitative variables, to compare between two studied groups. Ftest (ANOVA) was used for normally distributed quantitative variables, to compare between more than two groups. Pearson coefficient was used to correlate between two normally distributed quantitative variables. Reliability Statistics was assessed using Cronbach's Alpha test.

\section{Results}

Table (1) shows that the highest proportion of nursing students $(70.4 \%)$ were in the age group less than 21 years old, while the lowest proportion $(29.6 \%)$ were in the age group more than or equal 21 years old. Moreover, the majority of nursing students $(69.4 \%)$ were females and the minority (30.6\%) were males. Regarding study year in nursing Faculty, the highest percentage of nursing students $(37.3 \%)$ were third year nursing students followed by first and fourth year nursing students $(24.7 \%)$ while the lowest percentage $(13.3 \%)$ were second year nursing students. Also, those who had their clinical training in Alexandria 
Main University Hospital represented the highest percentage of nursing students (62.7\%), while the lowest percentage of nursing students had their clinical training in Alexandria Students' University Hospital $(3.1 \%)$. On the other hand, the highest percentage of nursing students had their clinical training in Medical Gastro-Intestinal Tract Departments (male and female) and Neurosurgical Department (male) (6.8\%), while the lowest percentage of nursing students had their clinical training in Neurological Intensive Care Unit and Second Intensive Care Unit $(0.6 \%, 0.9 \%)$ respectively. As regards type of clinical training, the highest percentage of nursing students $(38.0 \%)$ were trained in Medical surgical nursing specialty, followed by nursing students who were trained in Critical care and emergency nursing specialty $(12.7 \%)$ while the lowest percentage $(6.2 \%)$ of nursing students were trained in Nursing administration, Psychiatric nursing and mental health, Gerentological Nursing, and Community Health nursing specialties.

Table (2) illustrates that the mean score percentage of nursing students' perception of Clinical Learning Environment effectiveness was moderate $(67.77 \pm 18.26)$. The highest mean score percentage was for task orientation and satisfaction dimensions in their Clinical Learning Environment $(73.25 \pm 20.02$, and $71.89 \pm 22.16)$ respectively compared to the lowest mean score percentage $(58.62 \pm 21.41)$ for teaching innovation dimension in their Clinical Learning Environment.

Table (3) shows that the mean score percentage of nursing students' perception of their self-efficacy level in their Clinical Learning Environment was high

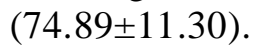

Table (4) illustrates that academic achievement level of the highest percentage of nursing students $(25.9 \%)$ was (B) $(80<85$ Grades in their nursing courses) followed by $(22.8 \%)$ of nursing students had (B+) ( $85<90$ Grades in their nursing courses). On the other hand, the academic achievement level of the lowest percentage of nursing students $(1.5 \%)$ was $(\mathrm{D}+)(55<60$ Grades in their nursing courses).

Table (5) shows that there were a statistically significant differences between nursing students' study year in nursing faculty, type of clinical training, clinical training unit and mean score percentage of nursing students' perception of clinical learning environment effectiveness $(\mathrm{F}=4.440, \quad \mathrm{P}=0.004, \quad \mathrm{~F}=2.374, \quad \mathrm{P}=0.022$, $\mathrm{F}=2.633, \mathrm{P}<0.001)$ respectively, in which the highest mean score percentage of nursing students' perception of clinical learning environment effectiveness was among fourth year nursing students (71.42 \pm 24.58$)$, nursing students who had their clinical training in community health nursing specialty $(74.14 \pm 19.38)$, and nursing students who had their clinical training in Female Psychiatric Department (84.40 \pm 2.60$)$. On the other hand, the lowest mean score percentage of nursing students' perception of clinical learning environment effectiveness was among second year nursing students $(59.88 \pm 12.23)$, nursing students who had their clinical training in Medical surgical nursing specialty (63.84 \pm 10.34$)$, and nursing students who had their clinical training in Medical Pediatric Department (53.85 \pm 25.71$)$. On the other hand, there was no statistically significant difference detected between nursing students' age, gender, and clinical training hospital and mean score percentage of nursing students' perception of clinical learning environment effectiveness.

Table (6) shows that there were a statistically significant differences between nursing students' age, Study year in nursing faculty, Clinical training hospital, Type of clinical training, Clinical training unit and mean score percentage of nursing students' self-efficacy $(\mathrm{F}=2.578, \mathrm{P}=0.011, \mathrm{~F}=11.404$, $\mathrm{P}<0.001, \quad \mathrm{~F}=2.359, \quad \mathrm{P}=0.040, \quad \mathrm{~F}=5.788$, $\mathrm{P}<0.001, \mathrm{~F}=2.724, \mathrm{P}<0.001)$ respectively, in which the highest mean score percentage of nursing students' self-efficacy was among 
nursing students who had more or equal 21 years old $(76.06 \pm 9.99)$, fourth year nursing students (79.75 \pm 3.58$)$, nursing students who had their clinical training in Alexandria New University Hospital (78.99 \pm 3.88$)$, nursing students who had their clinical training in Critical care and emergency nursing specialty $(78.81 \pm 4.61)$, and nursing students who had their clinical training in Female Psychiatric Department (80.76 \pm 5.96$)$. On the other hand, the lowest mean score percentage of nursing students' self-efficacy was among nursing students who had less than 21 years old $(72.10 \pm 13.58)$, first year nursing students $(70.42 \pm 11.66)$, nursing students who had their clinical training in El Shatby Pediatric Hospital (70.51 \pm 13.90$)$, nursing students who had their clinical training in pediatric nursing specialty (64.28 \pm 14.36 ), and nursing students who had their clinical training in Medical Pediatric Department (64.28 \pm 14.36$)$. On the other hand, there was no statistically significant difference detected between nursing students gender and mean score percentage of nursing students' self-efficacy.

Table (7) shows that there were statistically strong significant positive correlation between nursing students' perception of all subscales of clinical learning environment effectiveness (personalization, student involvement, satisfaction, task orientation, teaching innovation and individualization) and nursing students' self efficacy as $\mathrm{P}<0.05$. Moreover, there were statistically strong significant positive correlation between nursing students' perception of all subscales of clinical learning environment effectiveness (personalization, student involvement, satisfaction, task orientation, teaching innovation and individualization) and nursing students' academic achievement (GPA) as $\mathrm{P}<0.05$. Furthermore, there were statistically strong significant positive correlation between nursing students' selfefficacy and nursing students' academic achievement (GPA) as $\mathrm{P}<0.05$.

\section{Discussion}

Overall, more than two thirds of students were satisfied about their learning experiences from the clinical learning environment. The dimensions reported as more satisfied were task orientation, satisfaction and personalization. This may be related to that the clinical instructors provided orientation to students about what has to be done by them in this clinical setting, provided the students with clear instructions, the clinical tasks assigned to students are clear and carefully planned, the clinical placement is interesting for students and have a sense of satisfaction with this clinical placement, the clinical instructor considered the students' feelings, talks with them personally, help them during clinical training, solve the problems facing them during clinical training and rounded on them continuously.

The results of the current study are supported by Newton et al. (2010) who stated that students' satisfaction with Clinical Learning Environment mainly because they met their learning objectives, and availability of staff who assisted them during clinical training ${ }^{(26)}$. Moreover, study conducted by Framtz and Rhoda (2007) revealed that all students, experienced higher level of satisfaction with their clinical training experiences ${ }^{(27)}$. Also, this result is consistent with Kyei et al. (2014) who stated that the majority of students perceived their Clinical Learning Environment as rich in learning experiences because they exposed to different clinical training experiences ${ }^{(28)}$.

Students pointed out to the most unsatisfied dimensions with the clinical learning environment were teaching innovation, student involvement, and individualization. This is might be related to that duration of clinical rotation was too short, new ideas are seldom tried out by the clinical instructor with students during clinical training, different ways of clinical training are seldom used, innovative activities were not arranged for students, the assigned clinical activities for students were 
always the same, the clinical instructor did not plan interesting activities and the students performed the same type of tasks in during the clinical rotation, the clinical instructor talk rather than listen to students, and did not provide students with opportunities to express their opinions and interests, the clinical instructor does not negotiate with students when assigning their clinical activities. This result was consistent with other study conducted by Levett-Jones et al. (2006) who stated that students had less satisfaction with their clinical training experience because the duration of clinical rotation is too short and students were unfamiliar with the clinical training unit, and had fewer chances for effective clinical training $^{(29)}$.

Moreover, this result was consistent with Abouelfettoh and Al Mumtin (2015) who emphasized availability of clinical instructors who had competencies and skills in teaching and clinical training; provide effective assistance, and guidance for students at any time through difficult activities instead of providing negative criticism for students ${ }^{(30)}$.

More than two thirds of the nursing students had high academic self-efficacy level; this result was may be attributed to that the students affiliated to Faculty of nursing were provided with students' services and activities rendered to other students affiliated to all faculties of the university. Nursing students of this study provided with a separate building allocated for them and the building had the essential educational constituents (skills labs, computer labs, language labs, and halls to change clothes and places to eat and enough toilets to accommodate the number of students... etc). Students were also provided with Department of Youth Welfare in the Faculty of nursing to satisfy their needs for different Youth Welfare activities like the rest of the students' faculties of the university.
The result of the current study is consistent with another study conducted by Rezayat and Nayeri (2013) who stated that about $65 \%$ to $72 \%$ of the students had high level of self-efficacy ${ }^{(31)}$. Moreover, Karabacak et al. (2013) revealed that majority of the nursing students had a high self-efficacy level ${ }^{(32)}$. Furthermore, another study on associate degree nursing students conducted by Peterson-Graziose et al. (2013) revealed that $82 \%$ of these students had high level of self-esteem, and $77 \%$ stated high level of self-efficacy ${ }^{(33)}$. On the other hand, a study conducted by ALBaddareen and Ghaith (2013) entitled "Parenting Styles, Identity Styles and Academic Adjustment as Predictors of Academic Self-Efficacy among Hashemite University Students" revealed that Hashemite University' Students had moderate academic self-efficacy level ${ }^{(34)}$.

Participating in a class discussion, taking objective tests (MCQ, T/F \& matching), training in governorate hospital, participating in extracurricular events (sports, clubs), listen carefully during difficult lectures, teaching and training another student, writing high quality term papers, studying and revising lectures regularly, applying lecture content in clinical areas, taking well organized notes during lectures, explaining a concept to another student, attending class regularly, earning good marks in most courses, relating course content to material in other courses, understanding most ideas presented in class, asking a doctor or professor in class to review a concept you don't understand and making good use of library were recognized by high percentages of students as items for students' positive academic self-efficacy. These items were recognized as the main elements which help in achieving successful educational process, potentiate utilization of students' skills as problem solving, and critical thinking, encourage active rather than passive learning through using internet and recent literature in developing assignments which enhance confidence and independency among students. 
The result of the current study is consistent with Edwards et al. (2004) who stated that nursing students' confidence and self efficacy can be enhanced through effective Clinical Learning Environment ${ }^{(35)}$. Also, this result is in harmony with Bong (2001) who revealed that students who had a high level of self-efficacy develop competencies in applying academic tasks and feel more confidence of their capabilities $^{(36)}$. Moreover, this result goes in the same line with Lent et al. (2006) who stated that self efficacy can promote nursing students' educational strategies, and academic achievement $^{(37)}$.

Students expressed more satisfactions with clinical rotations of community health nursing course this might be mainly related to the uniqueness of skills, and experiences related to this specialty such as field trips, home visits in different rural areas, health education to students in different schools, visits to Maternity and Child Health Centers $(\mathrm{MCH})$, visits to factories for safety education to employees in addition to dynamicity and emergency of situations' that trigger problem solving ability, critical thinking and provide challenging opportunities for them. However, students reported less satisfaction with clinical rotation of Medical Surgical nursing courses this result could be due to that training in Medical Surgical nursing courses is the first experience of nursing students for clinical training in hospitals which may be viewed by nursing students as a stressful, and traumatic clinical experience as this was the first experience of students to contact with patients with different diagnosis and the nursing students were unfamiliar with clinical leaning environment. Also, this result may be attributed to that the large number of students in medical surgical training and shortage of clinical instructors where ratio was 1 clinical instructor to 25 students so the clinical instructor did not have enough time to provide continuous and effective feedback for students and did not provide opportunities for them to discuss and solve their problems.
The result of the current study is in harmony with Henriksen et al. (2012) who revealed that not all Clinical Learning Environment provide students with a positive learning experience ${ }^{(38)}$. Moreover, this result goes in the same line with Kajander-Unkuri, et al. (2014) who stated that students perceived clinical training experience as challenging, unpredictable and stressful especially in the first clinical training experience ${ }^{(39)}$.

Students also reported more satisfactions and academic self-efficacy of clinical placements in Critical and emergency nursing course. This could be explained as the students are provided with chances to learn new skills and competencies such as CVP measurement, CPR, and life basic support activities and trained to deal with complex and life threatening situations such as critical ill patients in critical and intensive care units which resulted in the nursing students become more confident and had a high level of their self efficacy and able to face challenges and difficult life threatening situations.

The result of the current study is in harmony with Kyei et al. (2014) who revealed that most of students stated that their Clinical Learning Environment were satisfying because they had the opportunity for various clinical training activities which resulted in nursing students had a higher confidence and self-efficacy level and became able to cope with challenges and manage life threatening situations effectively ${ }^{(28)}$.

The current study revealed significant positive correlation between nursing students' satisfactions of clinical learning environment effectiveness, students' self efficacy and their academic achievement. This result could be attributed to that clinical training of nursing students in effective clinical learning environment that characterized by adequate chances for students to apply theoretical knowledge into practice, presence of adequate and continuous feedback for students, presence 
of opportunities for students to learn competencies and skills such as basic life support activities resulted in the nursing students become self confident and had a higher level of self efficacy to deal with critical and complex patients and can provide high quality of patients' care and in turn their academic achievement improved . The result of the current study was in harmony with another study conducted by Long (2008) who revealed that the general self-efficacy level is a predictor for academic achievement of medical undergraduates $^{(40)}$.

Also, this result is consistent with Hwang et al. (2016) who revealed that past academic performance effect on selfefficacy beliefs was greater than selfefficacy beliefs effect on academic achievement $^{(41)}$. Moreover, a recent study done by Aung and Ye (2016) at Kant Kaw Education Center in Myanmar stated a positive correlation between students' satisfaction levels and their academic achievement $^{(42)}$. Also, another study conducted by Ergul (2004) revealed a significant positive correlation between students' self-efficacy and academic achievement $^{(43)}$. On the other hand, the result of the current study is inconsistent with Al Sebaee1 et al. (2017) study who didn't prove significant relationship between academic achievement of students and their self-efficacy ${ }^{(22)}$.

Statistical significant positive correlation was detected between nursing students' ages and their levels of self efficacy. This might be related to that as nursing students' progress in their study years they had more experience, more maturity, and trained in several and different Clinical Learning Environment so they had different competencies and capabilities and in turn their self efficacy level and self confidence increased and enable them to deal with difficult and complex situations.

The result of the current study is inconsistent with Karabacak et al. (2013) who revealed no statistically significant difference in students' self-efficacy level before and after skills training and students' age, gender, and educational level. Moreover, they stated that these results are due to environmental, cognitive and behavioral interaction processes which have impact on self-efficacy; therefore, individual's life experiences have effect on self-efficacy level rather than his or her $\operatorname{age}^{(44)}$.

\section{Conclusion}

The current study clarifies many positive and negative aspects of the clinical training experience as perceived by the nursing students. A supportive Clinical Learning Environment characterized by collaborative learning, trust and mutual respect. Furthermore, nursing students should be given chances to express their opinions about the positive and negative clinical training experiences. Measurement of nursing students' satisfaction about Clinical Learning Environment can be used to satisfy the needs of nursing students.

The current study revealed a mutual relationship between nursing students' satisfaction of Clinical Learning Environment, their selfefficacy and academic achievement. Therefore, clinical instructors should focus on effective measures that enhance effectiveness of Clinical Learning Environment and promote nursing students' self-efficacy and their academic achievement.

\section{Recommendations}

Based on the findings of this study, the following recommendations are suggested:

- Measurement of nursing students' satisfaction about the Clinical Learning Environment should be conducted in a compassionate and nonthreatening manner.

- Staff development programs for clinical instructors are needed to promote their skills in providing effective clinical training for nursing students.

- Opportunities should be allowed for nursing students to express their opinions about effectiveness of Clinical Learning Environment.

- The clinical instructors should assist nursing students to solve the problems facing them in the Clinical Learning Environment.

- Further researches are needed such as: developing an improvement strategy to enhance the effectiveness of Clinical Learning Environment. 
Table (1): Socio-demographic data for students $(n=324)$

\begin{tabular}{|c|c|c|c|}
\hline $\bar{Q}$ & Socio-demographic data for students & No. & $\%$ \\
\hline 1 & $\begin{array}{l}\text { Age } \\
<21 \\
\geq 21\end{array}$ & $\begin{array}{c}228 \\
96\end{array}$ & $\begin{array}{l}70.4 \\
29.6\end{array}$ \\
\hline 2 & \begin{tabular}{|l} 
Gender \\
Male \\
Female
\end{tabular} & $\begin{array}{c}99 \\
225\end{array}$ & $\begin{array}{l}30.6 \\
69.4\end{array}$ \\
\hline 3 & $\begin{array}{l}\text { Study year in nursing faculty } \\
\text { First year } \\
\text { Second year } \\
\text { Third year } \\
\text { Fourth year }\end{array}$ & $\begin{array}{c}80 \\
43 \\
121 \\
80\end{array}$ & $\begin{array}{l}24.7 \\
13.3 \\
37.3 \\
24.7\end{array}$ \\
\hline 4 & $\begin{array}{l}\text { Clinical training hospital } \\
\text { Alexandria Main University Hospital } \\
\text { Alexandria New University Hospital } \\
\text { Alexandria Students' University Hospital } \\
\text { El Shatby Pediatric Hospital } \\
\text { El Shatby Obestetric Hospital } \\
\text { El Maamoura Psychiatric Hospital }\end{array}$ & $\begin{array}{c}203 \\
11 \\
10 \\
40 \\
40 \\
20\end{array}$ & $\begin{array}{c}62.7 \\
3.4 \\
3.1 \\
12.3 \\
12.3 \\
6.2 \\
\end{array}$ \\
\hline 5 & $\begin{array}{l}\text { Clinical training unit } \\
\text { Medical Gastro-Intestinal Tract Department (male) } \\
\text { Medical Gastro-Intestinal Tract Department (female) } \\
\text { Medical Blood Diseases Department (male) } \\
\text { Medical Blood Diseases Department (female) } \\
\text { Surgical Gastro-Intestinal Tract Department (male) } \\
\text { Surgical Gastro-Intestinal Tract Department (female) } \\
\text { Neurosurgical Department (male) } \\
\text { Neurosurgical Department (female) } \\
\text { Thrid Intensive Care Unit } \\
\text { First Intensive Care Unit } \\
\text { Seventh floor Intensive Care Unit } \\
\text { Second floor General Intensive Unit } \\
\text { Medical Pediatric Department } \\
\text { Surgical Pediatric Department } \\
\text { Neonatal Intensive Care Unit (NICU) } \\
\text { Obstetric Family planning Unit } \\
\text { Obstetric Intensive Care Unit } \\
\text { Neurological Intensive Care Unit } \\
\text { Second Intensive Care Unit } \\
\text { Male Psychiatric Department } \\
\text { Female Psychiatric Department } \\
\text { Male Geriatric Department } \\
\text { Female Geriatric Department } \\
\text { Outpatient Department }\end{array}$ & $\begin{array}{c}22 \\
22 \\
11 \\
11 \\
11 \\
11 \\
22 \\
21 \\
14 \\
13 \\
11 \\
10 \\
15 \\
15 \\
10 \\
20 \\
20 \\
2 \\
3 \\
10 \\
10 \\
10 \\
10 \\
20\end{array}$ & $\begin{array}{c}6.8 \\
6.8 \\
3.4 \\
3.4 \\
3.4 \\
3.4 \\
6.8 \\
6.5 \\
4.3 \\
4.0 \\
3.4 \\
3.1 \\
4.6 \\
4.6 \\
3.1 \\
6.2 \\
6.2 \\
.6 \\
.9 \\
3.1 \\
3.1 \\
3.1 \\
3.1 \\
6.2\end{array}$ \\
\hline 6 & $\begin{array}{l}\text { Type of clinical training } \\
\text { Medical surgical nursing } \\
\text { Critical care and emergency nursing } \\
\text { pediatric nursing } \\
\text { Obstetric and gynecological nursing } \\
\text { Nursing administration } \\
\text { Psychiatric nursing and mental health } \\
\text { Gerentological Nursing } \\
\text { Community Health nursing }\end{array}$ & $\begin{array}{l}123 \\
41 \\
40 \\
40 \\
20 \\
20 \\
20 \\
20\end{array}$ & $\begin{array}{c}38.0 \\
12.7 \\
12.3 \\
12.3 \\
6.2 \\
6.2 \\
6.2 \\
6.2\end{array}$ \\
\hline
\end{tabular}


Table (2): Overall mean and SD of Clinical Learning Environment Inventory (CLEI) subscales $(\mathbf{n}=324)$

\begin{tabular}{||lc|c|c||}
\hline \hline Clinical Learning Environment Inventory & $\mathbf{M} \pm$ SD & Mean percent \\
(CLEI) subscales & Personalization & $26.52 \pm 5.55$ & $69.71 \pm 19.82$ \\
Student involvement & & $25.64 \pm 5.31$ & $66.57 \pm 18.98$ \\
Satisfaction & $27.13 \pm 6.21$ & $71.89 \pm 22.16$ \\
Task orientation & $27.51 \pm 5.60$ & $73.25 \pm 20.02$ \\
Teaching innovation & $23.41 \pm 5.99$ & $58.62 \pm 21.41$ \\
Individualization & $25.64 \pm 5.25$ & $66.58 \pm 18.76$ \\
\hline Overall & $155.85 \pm 30.67$ & $67.77 \pm 18.26$ \\
\hline \hline
\end{tabular}

Strength categories of nursing students' perception of Clinical Learning Environment effectiveness as the following:

$=\% 40<$ Low level of CLE effectiveness as perceived by nursing students

$=\% 69$ - \%40Moderate level of CLE effectiveness as perceived by nursing students

$=\% 70 \leq$ High level of CLE effectiveness as perceived by nursing students

Table (3): Overall mean and SD of College Academic Self Efficacy Scale $(n=324)$

\begin{tabular}{|l|c|c|}
\hline \multirow{2}{*}{ Self-efficacy } & $\mathbf{M} \pm$ SD & Mean percent \\
\cline { 2 - 3 } & $131.85 \pm 14.91$ & $74.89 \pm 11.30$ \\
\hline
\end{tabular}

Strength categories of nursing students' perception of their self-efficacy level in their Clinical Learning Environment as the following:

$=\% 40<$ Low level of nursing students' Self-Efficacy

$40 \%-69 \%=$ Moderate level of nursing students' Self-Efficacy

$\geq 70 \%=$ High level of nursing students' Self-Efficacy

Table (4): Students' academic achievement grades $(n=324)$

\begin{tabular}{||l|c|c||}
\hline Students' academic achievement grades & No. & $\%$ \\
\hline A $\geq 95$ Grades & 21 & 6.5 \\
A- 90 < 95 Grades & 34 & 10.5 \\
B+ 85 < 90 Grades & 74 & 22.8 \\
B $80<85$ Grades & 84 & 25.9 \\
B- 75 < 80 Grades & 48 & 14.8 \\
C $+70<75$ Grad es & 25 & 7.7 \\
C $65<70$ Grades & 18 & 5.6 \\
C- 60 < 65 Grades & 15 & 4.6 \\
D+ 55 <60 Grades & 5 & 1.5 \\
\hline
\end{tabular}


Table (5): Significance difference between socio-demographic data for students and their perception of clinical training environment effectiveness $(n=324)$

\begin{tabular}{|c|c|c|c|c|c|c|c|}
\hline \multirow[b]{2}{*}{$\begin{array}{l}\text { Socio-demographic data } \\
\text { for students }\end{array}$} & \multicolumn{7}{|c|}{ Clinical Learning Environment Inventory (CLEI) } \\
\hline & $\begin{array}{l}\text { Personaliz- } \\
\text { ation }\end{array}$ & $\begin{array}{c}\text { Student } \\
\text { involvement }\end{array}$ & Satisfaction & $\begin{array}{c}\text { Task } \\
\text { orientation }\end{array}$ & $\begin{array}{l}\text { Teaching } \\
\text { innovation }\end{array}$ & $\begin{array}{c}\text { Individualiz- } \\
\text { ation }\end{array}$ & Overall \\
\hline \multicolumn{8}{|l|}{$\overline{\text { Age }}$} \\
\hline $\mid<21$ & $68.89 \pm 17.81$ & $64.27 \pm 17.16$ & $71.01 \pm 20.33$ & $72.78 \pm 18.26$ & $56.91 \pm 20.11$ & $65.2 \pm 16.89$ & $66.52 \pm 16.20$ \\
\hline$\geq 21$ & $71.65 \pm 23.93$ & $72.02 \pm 21.87$ & $74.0 \pm 26.01$ & $74.37 \pm 23.74$ & $62.69 \pm 23.83$ & $69.75 \pm 22.35$ & $70.75 \pm 22.22$ \\
\hline$t(p)$ & $1.018(0.310)$ & $3.096(0.002)$ & $1.005(0.317)$ & $0.588(0.558)$ & $2.084(0.039)$ & $1.776(0.078)$ & $1.687(0.094)$ \\
\hline \multicolumn{8}{|l|}{ Gender } \\
\hline Male & $69.77 \pm 22.66$ & $67.78 \pm 21.45$ & $72.73 \pm 23.5$ & $72.73 \pm 22.52$ & $59.16 \pm 23.24$ & $66.5 \pm 21.03$ & $68.13 \pm 20.84$ \\
\hline Female & $69.68 \pm 18.49$ & $66.03 \pm 17.81$ & $71.52 \pm 21.58$ & $73.48 \pm 18.86$ & $58.38 \pm 20.60$ & $66.5 \pm 17.72$ & $67.61 \pm 17.05$ \\
\hline$t(p)$ & $0.033(0.973)$ & $0.712(0.477)$ & $0.450(0.653)$ & $0.310(0.757)$ & $0.303(0.762)$ & \begin{tabular}{|l|}
$0.010(0.992)$ \\
\end{tabular} & $0.217(0.829)$ \\
\hline \multicolumn{8}{|l|}{$\begin{array}{l}\text { Study year in nursing } \\
\text { faculty }\end{array}$} \\
\hline First year & $69.64 \pm 11.56$ & $61.12 \pm 11.69$ & $73.53 \pm 12.79$ & $73.26 \pm 13.19$ & $56.83 \pm 15.14$ & $61.43 \pm 10.45$ & $65.97 \pm 8.51$ \\
\hline Second year & $64.70 \pm 16.26$ & $55.65 \pm 13.64$ & $63.54 \pm 20.44$ & $71.01 \pm 15.71$ & $41.86 \pm 12.31$ & $62.54 \pm 13.53$ & $59.88 \pm 12.23$ \\
\hline Third year & $69.60 \pm 20.97$ & $69.75 \pm 18.28$ & $73.11 \pm 23.08$ & $74.73 \pm 20.48$ & $60.39 \pm 21.37$ & $68.51 \pm 19.77$ & $69.35 \pm 19.06$ \\
\hline Fourth year & $72.63 \pm 25.33$ & $73.08 \pm 24.01$ & $72.90 \pm 27.75$ & $72.19 \pm 26.24$ & $66.74 \pm 25.34$ & $70.98 \pm 24.02$ & $71.42 \pm 24.58$ \\
\hline $\mathbf{F}(\mathbf{p})$ & $\begin{array}{c}1.504 \\
(0.213) \\
\end{array}$ & $\begin{array}{c}12.403^{*} \\
\left(<0.001^{*}\right) \\
\end{array}$ & $\begin{array}{c}2.389 \\
(0.069) \\
\end{array}$ & $\begin{array}{c}0.474 \\
(0.701) \\
\end{array}$ & $\begin{array}{c}14.757^{*} \\
\left(<0.001^{*}\right) \\
\end{array}$ & $\begin{array}{c}4.729^{*} \\
\left(0.003^{*}\right) \\
\end{array}$ & $\begin{array}{l}4.440^{*} \\
\left(0.004^{*}\right) \\
\end{array}$ \\
\hline $\begin{array}{l}\text { Clinical training hospital } \\
\text { Alexandria Main } \\
\text { University Hospital }\end{array}$ & $69.11 \pm 18.16$ & $63.27 \pm 17.75$ & $71.18 \pm 20.54$ & $72.52 \pm 18.63$ & $55.81 \pm 20.12$ & $64.69 \pm 16.95$ & $66.09 \pm 16.34$ \\
\hline $\begin{array}{l}\text { Alexandria New University } \\
\text { Hospital }\end{array}$ & $60.39 \pm 16.17$ & $64.29 \pm 10.47$ & $68.83 \pm 15.98$ & $72.08 \pm 11.39$ & $46.75 \pm 9.90$ & $63.96 \pm 6.28$ & $62.72 \pm 7.71$ \\
\hline $\begin{array}{l}\text { Alexandria Students' } \\
\text { University Hospital }\end{array}$ & $61.07 \pm 16.01$ & $61.07 \pm 4.89$ & $77.86 \pm 15.87$ & $81.79 \pm 11.96$ & $55.0 \pm 12.51$ & $66.4 \pm 14.50$ & $67.20 \pm 8.87$ \\
\hline $\begin{array}{l}\text { El Shatby Pediatric } \\
\text { Hospital }\end{array}$ & $70.27 \pm 25.67$ & $70.62 \pm 21.30$ & $69.11 \pm 29.12$ & $71.70 \pm 25.87$ & $64.64 \pm 24.29$ & $68.66 \pm 25.47$ & $69.17 \pm 24.35$ \\
\hline $\begin{array}{l}\text { El Shatby Obestetric } \\
\text { Hospital }\end{array}$ & $74.73 \pm 20.16$ & $76.79 \pm 18.88$ & $76.79 \pm 22.49$ & $76.88 \pm 21.61$ & $65.80 \pm 23.67$ & $72.95 \pm 20.41$ & $73.99 \pm 20.36$ \\
\hline $\begin{array}{l}\text { El Maamoura Psychiatric } \\
\text { Hospital }\end{array}$ & $74.11 \pm 23.69$ & $75.54 \pm 23.81$ & $73.57 \pm 27.11$ & $72.86 \pm 23.93$ & $69.11 \pm 22.92$ & $70.3 \pm 21.65$ & $72.59 \pm 23.13$ \\
\hline $\mathbf{F}(\mathbf{p})$ & $\begin{array}{c}1.637 \\
(0.150) \\
\end{array}$ & $\begin{array}{c}5.342^{*} \\
\left(<0.001^{*}\right) \\
\end{array}$ & $\begin{array}{c}0.765 \\
(0.576) \\
\end{array}$ & $\begin{array}{c}0.734 \\
(0.598) \\
\end{array}$ & $\begin{array}{c}4.119^{*} \\
\left(0.001^{*}\right) \\
\end{array}$ & $\begin{array}{c}1.654 \\
(0.145) \\
\end{array}$ & $\begin{array}{c}1.788 \\
(0.115) \\
\end{array}$ \\
\hline Type of clinical training & & & & & & & \\
\hline $\begin{array}{l}\text { Medical surgical nursing } \\
\text { Critical care and } \\
\text { emergency nursing }\end{array}$ & $\begin{array}{l}67.92 \pm 13.53 \\
63.94 \pm 14.87\end{array}$ & $\begin{array}{l}59.20 \pm 12.62 \\
62.02 \pm 10.06\end{array}$ & $\begin{array}{l}70.03 \pm 16.51 \\
73.43 \pm 15.75\end{array}$ & $72.47 \pm 14.10$ & $\begin{array}{l}51.60 \pm 15.87 \\
50.96 \pm 10.50\end{array}$ & $\begin{array}{l}61.82 \pm 11.58 \\
64.02 \pm 9.66\end{array}$ & $\begin{array}{c}63.84 \pm 10.34 \\
65.0 \pm 8.18\end{array}$ \\
\hline Pediatric nursing & $70.27 \pm 25.67$ & $70.62 \pm 21.30$ & $69.11 \pm 29.12$ & $71.70 \pm 25.87$ & $64.64 \pm 24.29$ & $68.66 \pm 25.47$ & $69.17 \pm 24.35$ \\
\hline $\begin{array}{l}\text { Obstetric and } \\
\text { gynecological nursing }\end{array}$ & $74.73 \pm 20.16$ & $76.79 \pm 18.88$ & $76.79 \pm 22.49$ & $76.88 \pm 21.61$ & $65.80 \pm 23.67$ & $72.95 \pm 20.41$ & $73.99 \pm 20.36$ \\
\hline Nursing administration & $68.75 \pm 28.59$ & $70.54 \pm 26.85$ & $70.18 \pm 31.63$ & $68.57 \pm 30.36$ & $58.57 \pm 25.45$ & $68.75 \pm 28.09$ & $67.56 \pm 27.66$ \\
\hline $\begin{array}{l}\text { Psychiatric nursing and } \\
\text { mental health }\end{array}$ & $74.11 \pm 23.69$ & $75.54 \pm 23.81$ & $73.57 \pm 27.11$ & $72.86 \pm 23.93$ & $69.11 \pm 22.92$ & $70.36 \pm 21.65$ & $72.59 \pm 23.13$ \\
\hline Gerentological Nursing & $75.0 \pm 29.68$ & $72.14 \pm 27.61$ & $70.18 \pm 30.18$ & $70.71 \pm 29.42$ & $70.0 \pm 29.48$ & $70.36 \pm 28.05$ & $71.40 \pm 28.50$ \\
\hline Community Health nursing & $72.68 \pm 19.61$ & $74.11 \pm 18.21$ & $77.68 \pm 22.70$ & $76.61 \pm 21.57$ & $69.29 \pm 23.10$ & $74.46 \pm 18.33$ & $74.14 \pm 19.38$ \\
\hline $\mathbf{F}(\mathbf{p})$ & \begin{tabular}{|c|}
1.441 \\
$(0.188)$ \\
\end{tabular} & $\begin{array}{c}7.214^{*} \\
\left(<0.001^{*}\right) \\
\end{array}$ & \begin{tabular}{|c|}
0.762 \\
$(0.620)$ \\
\end{tabular} & \begin{tabular}{|c|}
0.608 \\
$(0.749)$ \\
\end{tabular} & \begin{tabular}{|c|}
$6.670^{*}$ \\
$\left(<0.001^{*}\right)$ \\
\end{tabular} & \begin{tabular}{|c|}
2.855 \\
$(0.007)$ \\
\end{tabular} & $\begin{array}{c}2.374^{*} \\
\left(0.022^{*}\right) \\
\end{array}$ \\
\hline
\end{tabular}


Table (5 continued): Significance difference between socio-demographic data for students and their perception of clinical training environment effectiveness $(n=324)$

\begin{tabular}{|c|c|c|c|c|c|c|c|}
\hline \multirow[b]{2}{*}{$\begin{array}{l}\text { Socio-demographic data } \\
\text { for students }\end{array}$} & \multicolumn{7}{|c|}{ Clinical Learning Environment Inventory (CLEI) } \\
\hline & ation & $\begin{array}{c}\text { Student } \\
\text { involvement }\end{array}$ & Satis & $\begin{array}{c}\text { Task } \\
\text { orientation }\end{array}$ & $\begin{array}{l}\text { Teaching } \\
\text { innovation }\end{array}$ & at & all \\
\hline \multicolumn{8}{|l|}{ Clinical training unit } \\
\hline Tract Depal & $68.67 \pm 16.68$ & $58.28 \pm 13.87$ & $70.45 \pm 16.32$ & $74.68 \pm 14.11$ & $53.73 \pm 16.03$ & $65.75 \pm 12.74$ & $65.26 \pm 11.77$ \\
\hline $\begin{array}{l}\text { Medical } \\
\text { Tract De }\end{array}$ & $68.99 \pm 16.29$ & $56.82 \pm 14.70$ & $68.99 \pm 21.27$ & $72.89 \pm 17.27$ & $52.92 \pm 19.55$ & $59.74 \pm 12.38$ & $63.39 \pm 13.88$ \\
\hline e) & $75.0 \pm 13.36$ & $62.66 \pm 10.02$ & $76.95 \pm 13.68$ & $70.13 \pm 16.92$ & $68.18 \pm 10.16$ & $59.74 \pm 9.6$ & $68.78 \pm 8.52$ \\
\hline $\begin{array}{l}\text { eases } \\
\text { e) }\end{array}$ & $72.08 \pm 9.01$ & $64.29 \pm 15.73$ & $79.22 \pm 17.7$ & $74.03 \pm 10.11$ & $59.74 \pm 13.08$ & $68.51 \pm 11.72$ & $69.64 \pm 10.14$ \\
\hline inal & $67.53 \pm 15.11$ & $58.44 \pm 14.40$ & $65.91 \pm 13.11$ & $62.01 \pm 16.07$ & $48.7 \pm 15.99$ & $56.82 \pm 10.65$ & $59.90 \pm 10.13$ \\
\hline Surgical & $71.43 \pm 8.45$ & $65.58 \pm 16.31$ & $73.05 \pm 12.61$ & $77.92 \pm 7.96$ & $50.65 \pm 12.56$ & $66.56 \pm 9.88$ & $67.53 \pm 8.67$ \\
\hline osurgical Department & $65.42 \pm 14.0$ & $60.23 \pm 11.73$ & $66.4 \pm 16.34$ & $73.21 \pm 14.15$ & $45.94 \pm 13.87$ & $64.12 \pm 12.25$ & $62.55 \pm 9.88$ \\
\hline e) & $65.82 \pm 14.31$ & $60.71 \pm 13.36$ & $69.05 \pm 20.15$ & $73.13 \pm 15.67$ & $46.94 \pm 15.54$ & $61.05 \pm 14.5$ & $62.78 \pm 12.64$ \\
\hline Unit & 6 & 0.13 & $72.7 \pm 2$ & & 6.23 & .24 & $63.52 \pm$ \\
\hline & & 8.57 & $69.78 \pm$ & & 7.34 & 60.1 & $63.83 \pm 18.15$ \\
\hline $\begin{array}{l}\text { floor Intensive } \\
t\end{array}$ & 60.3 & 64.29 & $68.83 \pm 15.98$ & $72.08 \pm$ & 46.75 & 63. & $62.72 \pm 7.71$ \\
\hline $\begin{array}{l}\text { or General } \\
\text { Unit }\end{array}$ & $61.07 \pm 16.01$ & $61.07 \pm 4.89$ & $77.86 \pm 15.87$ & $81.79 \pm 11.96$ & $55.0 \pm 12.51$ & $66.43 \pm 14.50$ & $67.20 \pm 8.87$ \\
\hline diatric & $55.48 \pm 27.16$ & $57.86 \pm 21.9$ & $50.24 \pm 32.01$ & $58.33 \pm 30.29$ & $46.9 \pm 21.84$ & $54.29 \pm 27.24$ & $53.85 \pm 25.71$ \\
\hline diatric & $72.62 \pm 23.68$ & $74.29 \pm 20.66$ & $75.71 \pm 25.55$ & $74.76 \pm 23.71$ & $68.33 \pm 21.63$ & $73.81 \pm 24.66$ & $73.25 \pm 22.44$ \\
\hline ensive Care & $88.93 \pm 8.66$ & $84.29 \pm 7.38$ & $87.5 \pm 4.84$ & 87. & $85.71 \pm 6.73$ & .44 & $86.01 \pm 4.82$ \\
\hline $\begin{array}{l}\text { Obstetric Family planning } \\
\text { Unit }\end{array}$ & $80.36 \pm$ & $82.14 \pm 6.13$ & $84.82 \pm 4.32$ & $84.82 \pm 7.68$ & $73.39 \pm 11.73$ & $79.82 \pm 7.17$ & $80.89 \pm 5.51$ \\
\hline \begin{tabular}{l||} 
Obstetric Intensive Care \\
Unit
\end{tabular} & $69.11 \pm 25.47$ & $71.43 \pm 25.17$ & $68.75 \pm 29.72$ & $68.93 \pm 27.69$ & $58.21 \pm 29.86$ & $66.07 \pm 26.54$ & $67.08 \pm 26.84$ \\
\hline $\begin{array}{l}\text { logical Intensive } \\
\text { Jnit }\end{array}$ & $82.14 \pm 5.05$ & $87.50 \pm 2.53$ & $78.57 \pm 0.0$ & $76.79 \pm 2.53$ & $67.86 \pm 10.10$ & $80.36 \pm$ & $60.77 \pm 28.51$ \\
\hline Care Unit & & 19 & & & & & \\
\hline niatric & 63 & .78 & $86.79 \pm$ & 39 & 77.8 & $81.07 \pm$ & $78.87 \pm 0.42$ \\
\hline $\begin{array}{l}\text { sychiatric } \\
\text { nt }\end{array}$ & $61.07 \pm 27.84$ & $63.93 \pm 29.18$ & $60.36 \pm 33.69$ & $59.29 \pm 27.93$ & $60.36 \pm 28.79$ & $59.64 \pm 26.78$ & $84.40 \pm 2.60$ \\
\hline Departm & & .99 & & & 82 & & 70 \\
\hline \begin{tabular}{l||l} 
Female Geriatric \\
Department
\end{tabular} & $77.50 \pm 24.46$ & $72.86 \pm 24.18$ & $72.14 \pm 30.39$ & $72.14 \pm 30.53$ & $69.64 \pm 29.75$ & $72.50 \pm 25.26$ & $72.80 \pm 27.01$ \\
\hline Outpatient Department & $72.68 \pm 19.61$ & $74.11 \pm 18.21$ & $77.68 \pm 22.7$ & $76.61 \pm 21.57$ & $69.29 \pm 23.10$ & $74.46 \pm 18.33$ & $74.14 \pm 19.38$ \\
\hline $\mathbf{F}(\boldsymbol{p})$ & $\begin{array}{l}2.178^{*} \\
\left(0.002^{*}\right)\end{array}$ & $\begin{array}{c}3.513^{*} \\
\left(<0.001^{*}\right)\end{array}$ & $\begin{array}{r}1.972^{*} \\
\left(0.006^{*}\right)\end{array}$ & $\begin{array}{l}1.788^{*} \\
\left(0.016^{*}\right)\end{array}$ & $\begin{array}{c}4.442^{*} \\
\left(<0.001^{*}\right)\end{array}$ & $\begin{array}{c}2.456^{*} \\
\left(<0.001^{*}\right) \\
\end{array}$ & $\begin{array}{c}2.633^{*} \\
\left(<0.001^{*}\right)\end{array}$ \\
\hline
\end{tabular}

F: F for ANOVA test

$p: p$ value for associated between different categories

*: Statistically significant at $p \leq 0.05$ 
Table (6): The relationship between socio-demographic data for students and their self-efficacy

\begin{tabular}{|c|c|}
\hline Socio-demographic data for students $(n=324)$ & Self Efficacy \\
\hline \multicolumn{2}{|l|}{ Age } \\
\hline$<21$ & $72.10 \pm 13.58$ \\
\hline$\geq 21$ & $76.06 \pm 9.99$ \\
\hline$t(p)$ & $2.578^{*}\left(0.011^{*}\right)$ \\
\hline \multicolumn{2}{|l|}{ Gender } \\
\hline Male & $73.97 \pm 11.64$ \\
\hline Female & $75.29 \pm 11.15$ \\
\hline $\mathbf{t}(\mathbf{p})$ & $0.967(0.334)$ \\
\hline \multicolumn{2}{|l|}{ Study year in nursing faculty } \\
\hline First year & $70.42 \pm 11.66$ \\
\hline Second year & $71.12 \pm 15.22$ \\
\hline Third year & $75.76 \pm 10.09$ \\
\hline Fourth year & $79.75 \pm 3.58$ \\
\hline $\mathbf{F}(\mathbf{p})$ & $11.404^{*}\left(<0.001^{*}\right)$ \\
\hline \multicolumn{2}{|l|}{ Clinical training hospital } \\
\hline Alexandria Main University Hospital & $74.67 \pm 11.64$ \\
\hline Alexandria New University Hospital & $78.99 \pm 3.88$ \\
\hline Alexandria Students' University Hospital & $78.64 \pm 4.61$ \\
\hline El Shatby Pediatric Hospital & $70.51 \pm 13.90$ \\
\hline El Shatby Obestetric Hospital & $77.88 \pm 7.44$ \\
\hline El Maamoura Psychiatric Hospital & $75.76 \pm 11.07$ \\
\hline $\mathbf{F}(\mathbf{p})$ & $2.359^{*}\left(0.040^{*}\right)$ \\
\hline \multicolumn{2}{|l|}{ Type of clinical training } \\
\hline Medical surgical nursing & $76.49 \pm 8.67$ \\
\hline Critical care and emergency nursing & $78.81 \pm 4.61$ \\
\hline Pediatric nursing & $64.28 \pm 14.36$ \\
\hline Obstetric and gynecological nursing & $77.88 \pm 7.44$ \\
\hline Nursing administration & $70.95 \pm 16.05$ \\
\hline Psychiatric nursing and mental health & $75.76 \pm 11.07$ \\
\hline Gerentological Nursing & $73.48 \pm 17.31$ \\
\hline Community Health nursing & $70.51 \pm 13.90$ \\
\hline $\mathbf{F}(\mathbf{p})$ & $5.788^{*}\left(<0.001^{*}\right)$ \\
\hline \multicolumn{2}{|l|}{ Clinical training unit } \\
\hline Medical Gastro-Intestinal Tract Department (male) & $72.11 \pm 11.92$ \\
\hline Medical Gastro-Intestinal Tract Department (female) & $73.31 \pm 11.25$ \\
\hline Medical Blood Diseases Department (male) & $78.72 \pm 3.33$ \\
\hline Medical Blood Diseases Department (female) & $78.1 \pm 5.57$ \\
\hline Surgical Gastro-Intestinal Tract Department (male) & $77.34 \pm 10.7$ \\
\hline Surgical Gastro-Intestinal Tract Department (female) & $79.06 \pm 5.12$ \\
\hline Neurosurgical Department (male) & $76.83 \pm 8.08$ \\
\hline Neurosurgical Department (female) & $76.98 \pm 6.02$ \\
\hline Thrid Intensive Care Unit & $79.55 \pm 5.09$ \\
\hline First Intensive Care Unit & $74.71 \pm 14.4$ \\
\hline Seventh floor Intensive Care Unit & $78.99 \pm 3.88$ \\
\hline Second floor General Intensive Unit & $78.64 \pm 4.61$ \\
\hline Medical Pediatric Department & $64.28 \pm 14.36$ \\
\hline Surgical Pediatric Department & $66.36 \pm 15.22$ \\
\hline Neonatal Intensive Care Unit (NICU) & $66.44 \pm 19.84$ \\
\hline Obstetric Family planning Unit & $79.62 \pm 4.51$ \\
\hline Obstetric Intensive Care Unit & $76.14 \pm 9.33$ \\
\hline Neurological Intensive Care Unit & $75.76 \pm 26.78$ \\
\hline Second Intensive Care Unit & $71.72 \pm 23.65$ \\
\hline Male Psychiatric Department & $70.76 \pm 12.95$ \\
\hline Female Psychiatric Department & $80.76 \pm 5.96$ \\
\hline Male Geriatric Department & $70.91 \pm 12.88$ \\
\hline Female Geriatric Department & $80.53 \pm 11.32$ \\
\hline Outpatient Department & $74.39 \pm 12.85$ \\
\hline $\mathbf{F}(\mathbf{p})$ & $2.724^{*}\left(<0.001^{*}\right)$ \\
\hline
\end{tabular}


Table (7): Correlation matrix between students' perception of clinical learning environment effectiveness, students' self efficacy and academic achievement $(n=324)$

\begin{tabular}{|l|c|c|c|c||}
\hline \multirow{2}{*}{ Self-Efficacy } & \multicolumn{2}{|c|}{ Self-Efficacy } & \multicolumn{2}{c|}{$\begin{array}{c}\text { Academic achievement } \\
\text { (GPA) }\end{array}$} \\
\cline { 2 - 5 } & $\mathbf{r}$ & $\mathbf{p}$ & $\mathbf{r}$ & $\mathbf{p}$ \\
\hline Learning Environment Inventory & & & $0.127^{*}$ & $0.022^{*}$ \\
Personalization & $0.207^{*}$ & $<0.001^{*}$ & $0.180^{*}$ & $0.001^{*}$ \\
Student involvement & $0.178^{*}$ & $0.001^{*}$ & $0.193^{*}$ & $<0.001^{*}$ \\
Satisfaction & $0.233^{*}$ & $<0.001^{*}$ & $0.132^{*}$ & $0.018^{*}$ \\
Task orientation & $0.244^{*}$ & $<0.001^{*}$ & $0.135^{*}$ & $0.015^{*}$ \\
Teaching innovation & $0.128^{*}$ & $0.021^{*}$ & $0.186^{*}$ & $<0.001^{*}$ \\
Individualization & $0.213^{*}$ & $<0.001^{*}$ & $0.220^{*}$ & $<0.001^{*}$ \\
\hline Overall & $0.222^{*}$ & $<0.001^{*}$ & $0.208^{*}$ & $<0.001^{*}$ \\
\hline
\end{tabular}

$r$ : Pearson coefficient

*: Statistically significant at $p \leq 0.05$ 


\section{References}

1. Cote L, Leclere H. How clinical teachers perceive the doctor-patient relationship and themselves as role models. Acad Med. 2000; 75 (11):1117-1124.

2. Al-Ayed I, and Sheik A. Assessment of the educational environment at the College of Medicine of King Saud University. Riyadh Eastern Mediterranean Health Journal 2008; 14(4): 953-59.

3. Papastavrou E, Lambrinou E, Tsangari H, Saarikoski M, and Leino-Kilpi H. Student nurses experience of learning in the clinical environment. Nurse Education in Practice 2010; 10: 176-182.

4. Zakaria A, Gheith N. Measurement of Effectiveness of Clinical Learning Environment for Nursing Faculty Students at Mansoura University, Egypt. Journal of Nursing and Health Science 2015; 4(3): 3545.

5. Rahmani A, Zamanzadeh V, Abdullah-zadeh F, Lotfi M, Bani S, Hassanpour S. Clinical learning environment in viewpoint of nursing students in Tabriz University of Medical Sciences. Iran J Nurs Midwifery Res. 2011; 16(3):253 - 256.

6. Sherwood G, Drenkard K. Safety and quality curricula for nursing education: Matching practice realities. Nursing Outlook 2007; 55(3): 151-55.

7. Ghodsbin F, Shafakhah M. Facilitating and Preventing Factors in Learning Clinical Skills from the Viewpoints of the Third Year Students of Fatemeh School of Nursing and Midwifery. Iranian Journal of Medical Education 2008; 7(2):343-52.

8. Papp I, Markkanen M, and Von Bonsdorff M. Clinical environment as a learning environment: Student nurses' perceptions concerning clinical learning experiences. Nurse Education Today 2003; 23: 262-268.

9. Edwards H, Smith S, Courtney M, Finlayson $\mathrm{K}$, and Chapman $\mathrm{H}$. Impact of clinical placement location on nursing students' competence and preparedness for practice. Nurse Education Today 2004; 24(4):248-255

10. Arbabisarjou A, Zare S, Shahrakipour M and Ghoreishinia G. Relationship between Self-Efficacy and Academic Achievement of Zahedan: Medical Sciences Students. International Journal of Medical Research \&Health Sciences 2016; 5, 7S:349-53.

11. Hwang M, Choi H, Lee A, Culver J, and Hutchison B. The relationship between selfefficacy and academic achievement: A 5-year panel analysis. The Asia-Pacific Education Researcher 2016; 25(I): 89-98.

12. Hosseini MA, Dejkam M, Mirlashari J. Correlation between Academic Achievement and Self-esteem in Rehabilitation Students in Tehran University of Social Welfare \& Rehabilitation. Iranian journal of medical education 2007; 7(1): 137-42.

13. Yusuf M. The impact of self-efficacy, achievement motivation, and self regulated learning strategies on students' academic achievement. Procedia-Soc Behav Sci. 2011; 15: 2623-6.

14. Z.-J. Zhang et al. Relationship between selfefficacy beliefs and achievement motivation in student nurses. Chinese Nursing Research 2015; 2: 67-70.

15. Zahra Taheri-Kharameh et al. Relationship between Academic Self-efficacy and Motivation among Medical Science Students. Journal of Clinical and Diagnostic Research 2018; 12(7): JC07-JC10.

16. Akademik H, Yeterlikleri M. Academic Motivations and Academic Self-Efficacy of Nursing Students. Journal of Clinical and Analytical Medicine 2017; 8(1): 47-51

17. Zengin N, Pinar R, Akinci AC, Yildiz H. Psychometric properties of the self-efficacy for clinical evaluation scale in Turkish nursing students. J Clin Nurs. 2014; 23(7-8): 976-84.

18. McLaughlin K, Moutray M, Muldoon OT. The role of personality and self-efficacy in the selection and retention of successful nursing students: a longitudinal study. J Adv Nurs. 2008; 61(2):211-21.

19. Stump GS, Husman J, Brem SK. The Nursing Student Self-Efficacy Scale: Development using item response theory. Nurs Res. 2012; 61(3):149-58.

20. McLaughlin K, Moutray M, Muldoon OT. The role of personality and self-efficacy in the selection and retention of successful nursing students: a longitudinal study. J Adv Nurs. 2008; 61(2):211-21.

21. Gibbons C. Stress, coping and burn-out in nursing students. Int J Nurs Stud. 2010; 47(10):1299-309.

22. Al Sebaee1 H, Abdel Aziz E, Mohamed N. Relationship between Nursing Students' Clinical Placement Satisfaction, Academic Self-Efficacy and Achievement. IOSR Journal of Nursing and Health Science 2017; 6(2): 101-112.

23. Chan DSK. Combining qualitative and quantitative methods in assessing hospital 
learning environments. International Journal of Nursing Studies 2001; 38: 447-59.

24. Chan D. Development of the clinical learning environment inventory: using the theoretical framework of learning environment studies to assess nursing students' perceptions of the hospital as a learning environment. Journal of Nursing Education 2002; 41: 69-75.

25. Owen S, Froman R. Development of a college academic self-efficacy scale. Paper presented at the 1998 annual meeting of the National Council on Measurement in Education.

26. Newton J, Jolly B, Ockerby C, and Cross W. Clinical learning inventory: Factor analysis. Journal of Advanced Nursing 2010; 66(6):1371-81.

27. Framtz $\mathbf{J}$ and Rhoda A. Assessing Clinical Placements in a B.Sc. Physiotherapy Program. The Internet Journal of Allied Health Sciences and Practice 2007; 5(3):1224.

28. Kyei K, Bruce A, Antwi W, and David N. Impact of clinical placement on radiography students in Ghana. International Journal of Medical Research \& Health Sciences 2014; 3(4): 819-24.

29. Levett-Jones T, Fahy K, Parsons K, and Mitchell A. Enhancing nursing students' clinical placement experiences: a quality improvement project. Contemporary Nurse 2006; 23:58-71.

30. Abouelfettoh A, and Al Mumtin S. Nursing students' satisfaction with their clinical placement. Journal of Scientific Research \& Reports 2015; 4(6): 490-500.

31. Rezayat F and Nayeri N. Self-Efficacy after Life Skills Training: A Case-Control Study. Nursing and Midwifery Studies 2013, 2(4): 83-8.

32. Karabacak Ü, Serbest, Ş, KanÖntürk Z, EtiAslan F, and Olgun N. Relationship between student nurses' self-efficacy and psychomotor skills competence. International Journal of Nursing Practice 2013; 19: 124130.

33. Peterson-Graziose V, Bryer J, and Nikolaidou M. Self-esteem and self-efficacy as predictors of attrition in associate degree nursing students. Journal of Nursing Education 2013; 52(6):351-4.

34. AL-Baddareen $\mathrm{G}$ and Ghaith S. Parenting styles, identity styles and academic adjustment as predictors of academic selfefficacy among Hashemite university students. Jordanian Journal of Educational Sciences, Amman 2013; 9(1): 65 -87.
35. Edwards H, Smith S, Courtney M, Finlayson $\mathrm{K}$, and Chapman H. Impact of clinical placement location on nursing students' competence and preparedness for practice. Nurse Education Today 2004; 24(4):248-55.

36. Bong M. Role of self-efficacy and task-value in predicting college students' course performance and future enrollment intentions. Contemporary educational psychology. Elsevier 2001; 26(4): 553-570.

37. Lent RW, Schmidt J, Schmidt L. Collective efficacy beliefs in student work teams: Relation to self-efficacy, cohesion, and performance. Journal of Vocational Behavior. Elsevier 2006; 68(1): 73-84.

38. Henriksen N, Normann H, and Skaalvik M. Development and Testing of the Norwegian Version of the Clinical Learning Environment, Supervision and Nurse Teacher (CLES+T) Evaluation Scale. International Journal of Nursing Education Scholarship 2012; 9 (1): 334-50.

39. Kajander-Unkuri S, Meretoja R, Katajisto J, Saarikoski L, Suhonen R, and Leino-Kilpi H. Self-assessed level of competence of graduating nursing students and factors related to it. Nurse Education Today 2014; 34: 795-801.

40. Long B. Medical undergraduates effect of general self-efficacy on study result. China. Journal of Health Psychology 2008; 16(5):483-4.

41. Hwang M, Choi H, Lee A, Culver J, and Hutchison B. The relationship between selfefficacy and academic achievement: A 5-year panel analysis. The Asia-Pacific Education Researcher 2016; 25(I): 89-98.

42. Aung J, and Ye Y. The relationship between the levels of students' satisfaction and their achievement at Kant Kaw education center in Myanmar. $2016 . \quad$ Available at: www.assumptionjournal.au.edu/index.php/Sc holar/article/download/2184/1533. Retrieved on: (23\6\2019).

43. Ergul H. Relationship between students' characteristics and academic achievement in distance education and application to students of Anadolu University in Turkish. Online Journal of Distance Education 2004; 5(2): 5569.

44. Karabacak Ü, Serbest Ş, KanÖntürk Z, EtiAslan F, and Olgun N. Relationship between student nurses' self-efficacy and psychomotor skills competence. International Journal of Nursing Practice 2013; 19: 124130. 